\title{
A construção coletiva de uma proposta de conteúdos curriculares de Ecologia para o Ensino Médio na formação inicial de professores com suportes da História da Ciência
}

\section{The collective construction of a proposal of curricular content on Ecology for High School in the initial formation of teachers with the support of History of Science}

\author{
${ }^{1}$ João Augusto dos Reis Neto \\ ${ }^{1}$ Marco Túlio Mendes Ferreira \\ ${ }^{1}$ Taís Silva \\ ${ }^{1}$ Antonio Fernandes Nascimento Junior
}

\section{RESUMO}

O presente trabalho visa apresentar uma proposta de conteúdos curriculares de Ecologia, para o ensino médio, construído por licenciandos do curso de Licenciatura em Ciências Biológicas da Universidade Federal de Lavras - MG, no âmbito da disciplina de "Metodologia do ensino em Ecologia". A proposta aqui apresentada, embasada na teoria crítica do currículo e utilizando a História da Ciência como eixo norteador da proposta, toma como referência os Parâmetros Curriculares Nacionais afim de construir uma nova proposta de currículo que compreenda tanto a formação científica quanto a formação da cidadania dos educandos. Após ser finalizada, a proposta, foi comparada ao currículo oficial adotado pelas escolas estaduais do município de Lavras, e aos livros didáticos utilizados por elas. A partir desta avaliação podemos perceber que o currículo oficial é, em muitos aspectos, fragmentado e pouco contextualizado. Sendo assim, compreendemos que é necessário propormos novas formas de (re)pensar e construir o currículo, como em nossa proposta, tentando contribuir para que os educandos e educandas construam seu conhecimento a partir de situações que façam sentido em sua realidade e que os possibilite interpretar e intervir nos processos históricos, políticos, econômicos e sociais.

Palavras-chaves: ensino de ecologia; proposta curricular; metodologia de ensino em ecologia.

\section{ABSTRACT}

This paper presents a proposal of a curriculum on Ecology for high school, built by undergraduates in Biological Sciences of Federal University of Lavras - MG, within the course "Teaching methodology in Ecology". The proposed curriculum, based on the critical theory of the curriculum and using the History of Science as a guideline, has referred to the National Curriculum Parameters in order to build a new curriculum proposal to comprise both scientific training and the formation of citizenship of students. After being finalized, the proposed curriculum was compared to the official curriculum adopted by the state schools in

1 UFLA - Universidade Federal de Lavras, Lavras, MG. 
the city of Lavras, and the textbooks they use. From this assessment, we realized that the official curriculum is, in many ways, fragmented and poorly contextualized. Thus, we understand that it is necessary to propose new ways to (re) think and build the curriculum, as in our proposal, trying to provide the students with the ability to build their knowledge in situations that make sense in their reality and that enables them to interpret and intervene in historical, political, economic and social processes.

Keywords: teaching of ecology; curriculum proposal; teaching methodology in ecology.

\section{INTRODUÇÃO}

Ao longo da história surgiram diferentes concepções de currículo, desde correntes tradicionais até as mais progressistas. Neste trabalho gostaríamos de destacar as teorizações feitas a partir da segunda metade do século XX (SILVA, 2006) por compreendermos que as correntes teóricas críticas desta época dialogam intimamente com uma perspectiva progressista e libertária que acreditamos ser necessária construirmos para a educação. Sendo assim, para que se compreenda como o currículo vem sendo discutido a partir das teorizações do século XX, evidenciamos a década de 1960, onde há uma forte crítica ao modelo de funcionamento da sociedade capitalista e o papel da escola nessa sociedade (SILVA, 2006).

Diante disso, segundo a mesma autora, houve abertura para a discussão do currículo e o surgimento de novas perspectivas de estudo. Assim, as discussões passaram a avaliar o modo como a escola se insere no cenário capitalista e, especificamente, como ela se organiza e funciona. Além disso, o currículo é foco de preocupação, pois nele se materializa as relações de poder da sociedade. Vale ressaltar que essa crítica, em grande parte, advém dos movimentos sociais de diversas partes do mundo que expressaram a sua insatisfação com o modelo de escola vigente, isto é, o modelo de escola excludente, seletiva e esvaziada de conteúdos com significados vitais e (SILVA, 2006).

A teoria crítica do currículo combate a ideia de neutralidade do currículo assumindo a estreita relação existente com a cultura, as ideologias e as relações de poder na sociedade, além de propor a ideia de resistência à hegemonia social instalada no interior da sociedade capitalista. Segundo Moreira e Silva (1997), o currículo não é uma listagem aleatória de conhecimentos agrupados em um índice, é na verdade, um instrumento político, um artefato social e cultural, que dialoga com ideologias, cultura(s), estrutura social e poder. Nessa perspectiva, o currículo não é uma sistematização de conteúdos e habilidades, mas sim um campo de disputa de poder, afirmação e resistência. Nesse sentido, é necessário que haja um debruçar sobre essas questões a fim de construirmos uma educação que fomente a crítica e autonomia dos educandos preparando-os para a vida em sociedade, e que viabilize as transformações sociais que almejamos. Para isso é preciso que essas questões acerca do currículo estejam presentes na formação de professores, pois estes necessitam de uma nova leitura de mundo e da condição humana para compreender a dinâmica social-educacional-política-cultural da sociedade contemporânea (SANTOS, 2008). Nessa perspectiva, os alunos do curso de Licenciatura em Ciências Biológicas da Universidade Federal de Lavras - MG, em um exercício pedagógico na disciplina de "Metodologia do Ensino de Ecologia" construíram uma proposta de currículo para se ensinar Ecologia para alunos do Ensino Médio.

Os conceitos de Ecologia, baseados na história natural da terra prestam-se como mediadores na visão de mundo dos sujeitos. Assim, a proposta deste currículo presta-se, na atual sociedade ocidental capitalista, como uma contracultura do consumismo, da ideia de natureza como recurso e do fixismo. Contudo, para que cumpra esse papel, é necessário que as práticas pedagógicas envolvidas também sejam orientadas criticamente, valorizando a contextualização, a história e a filosofia da ciência. Além disso, é necessário que essas práticas sejam pensadas de forma a desenvolver no sujeito a autonomia, a visão histórica dos processos sociais e naturais, e as relações de poder na sociedade. Desse modo, a construção deste currículo deu-se de forma a contemplar estas orientações considerando a dimensão plural do ensino e levando em conta o papel da ecologia na formação do sujeito. 


\section{OBJETIVO}

O presente trabalho tem como objetivo relatar a construção de uma proposta de currículo para o ensino de Ecologia no ensino médio. Além disso, pretende discutir questões acerca da concepção da proposta elaborada pelos alunos e a sua relação com a atual conjuntura do modelo de educação vigente.

\section{METODOLOGIA - O DESENVOLVIMENTO DO TRABALHO}

\section{1 Descrição das atividades da disciplina e a construção do currículo}

A disciplina "Metodologia do Ensino de Ecologia" foi oferecida no primeiro semestre de 2014 e teve como participantes os licenciandos matriculados. Ao longo do semestre os vinte e sete alunos desenvolveram, inicialmente em grupos e depois todos reunidos, uma proposta de conteúdos curriculares de Ecologia para o Ensino Médio, a partir da história natural da Terra, tendo a História da Ciência como estratégia. Isso pelo fato de que a História da Ciência, possibilita uma contextualização da informação dos conceitos e teorias científicas, o que possibilita e enriquece a compreensão conceitual (DUARTE, 2004). Além de nos colocar em contato com a historicidade dos conhecimentos, nos permitindo compreender os outros elementos sociais que compõe uma teoria ou conceito científico.

Inicialmente os alunos foram orientados a ler sobre o que é currículo e suas teorias, sua concepção e construção, além de textos sobre a História da Ciência e sua utilização no ensino de ciências, e sobre a História da Ecologia. Essa leitura subsidiou uma discussão inicial que deu origem aos primórdios da concepção da proposta elaborada pelos licenciandos. Nesse processo entendeu-se que a História Natural poderia auxiliar a compreensão da história social da ecologia. Nas aulas que se seguiram foram discutidos os conteúdos que deveriam compor o currículo, a partir das leituras realizadas. Após uma série de aulas a proposta foi organizada.

Uma vez os conteúdos selecionados, a partir combinação da História da Terra (a história dos eventos naturais que ocorreram no planeta ao longo do tempo) e da História da Ecologia (vale ressaltar, que consideramos para a realização deste trabalho, o desenvolvimento da Ecologia como uma área específica da Ciência), e com base nos textos utilizados na disciplina, procuramos relacionar, e posteriormente comparar, o currículo proposto aos PCN (BRASIL, 2000) e ao Currículo Básico Comum (MINAS GERAIS, 2007) que é adotado pelas escolas estaduais do estado de Minas Gerais. O CBC é um documento oficial, elaborado pela Secretaria de Estado de Educação, que contém indicação dos conteúdos e as habilidades que devem ser trabalhados no ensino fundamental e médio. Este documento é que norteia oficialmente a prática dos professores da rede estadual de ensino no estado de Minas.

Além disso, a nossa proposta de conteúdos curriculares foi comparada também com os livros didáticos do ensino médio utilizados na rede estadual de ensino do município de Lavras-MG. Esses paralelos foram feitos a fim de compreender a relação entre a proposta de currículo que havia sido elaborada pelos licenciandos e o atual modelo de currículo que é trabalhado nas escolas estaduais do município de Lavras - MG, que seguem o CBC e os livros didáticos.

\section{RESULTADOS E DISCUSSÃO}

Após as discussões realizadas em aula, e os estudos relacionadas à temática, conseguimos compor a nossa proposta de conteúdos curriculares de ecologia, conforme apresentada no Quadro 1. 


\section{Quadro 1 - Proposta de conteúdos curriculares de ecologia feita pelos alunos na disciplina "Metodologia do Ensino em Ecologia".}

\begin{tabular}{|l|l|}
\hline Item & Temas \\
\hline 01 & História da ecologia (O termo Ecologia/ Geobotânicos X Evolucionista) \\
\hline 02 & Habitat \\
\hline 03 & Biocenose e Comunidade \\
\hline 04 & Níveis Tróficos e Conceito Trófico Dinâmico da Ecologia \\
\hline 05 & Nicho Ecológico \\
\hline 06 & Teorias Policlímax, Monoclímax e Sucessão Ecológica \\
\hline 07 & Ecossistema \\
\hline 08 & Ecologia Humana \\
\hline 09 & Ecologia da paisagem \\
\hline 10 & Forrageio ótimo (Teoria da otimização e energética) \\
\hline 11 & População e Metapopulação \\
\hline 12 & Biodiversidade \\
\hline 13 & Biogeografia de Ilhas \\
\hline 14 & Interações ecológicas \\
\hline
\end{tabular}

Fonte: dos autores.

\section{1 Relação do currículo proposto com os PCN}

De acordo com o PCN do Ensino Médio (1998), especificamente no de "Ciências da Natureza, Matemática e suas Tecnologias”, o conhecimento biológico deve subsidiar o julgamento de questões polêmicas, que dizem respeito ao desenvolvimento, ao aproveitamento de recursos naturais e à utilização de tecnologias que implicam intensa intervenção humana no ambiente, cuja avaliação deve levar em conta o modo como a natureza se comporta e a vida se processa (BRASIL, 1999). O PCN (BRASIL, 1998) sugere trabalhar com os conteúdos referentes à Ecologia de forma articulada com a evolução, tratando de uma forma histórica e mostrando que distintos períodos e escolas de pensamento abrigaram diferentes ideias sobre o surgimento e manutenção da vida na Terra. Ainda, deve-se relacioná-las ao momento histórico em que foram elaboradas, reconhecendo os limites de cada uma delas na explicação e para o entendimento do fenômeno.

Ainda de acordo com os PCN, é necessário ainda que os estudantes compreendam que a presença humana pode interferir no equilíbrio dos ecossistemas. Como organismo integrante do fluxo e ciclos que operam nos ecossistemas a humanidade produz modificações intencionais e constrói novos ambientes. Estudar a ocupação humana permite aos alunos compreender e julgar modos de realizar tais intervenções, estabelecendo relações com fatores sociais, políticos, culturais e econômicos envolvidos. Possibilita, ainda, o estabelecimento de relações entre intervenção no ambiente, degradação ambiental e agravos à saúde humana e a avaliação do desenvolvimento sustentável como alternativa ao modelo atual.

A proposta curricular desenvolvida na Metodologia de Ensino de Ecologia se relaciona diretamente com a proposta colocada pelos PCN de Ciências da Natureza, Matemática e suas Tecnologias do Ensino Médio (1999), pois esta foi construída numa perspectiva contextualizada, levando em consideração os elementos que circundam a prática educativa e os conteúdos curriculares. Segundo os PCN (BRASIL, 1999) as atividades e os temas de estudo de Ciências Naturais devem ser organizados para que os estudantes ganhem progressivamente várias capacidades distintas e ampliem suas possibilidades de compreensão e participação efetiva no mundo. Estes foram os objetivos centrais considerados na construção do currículo de Ecologia na disciplina, que tem como alvo alunos do Ensino Médio. 
A nossa proposta visava integrar as principais competências e habilidades propostas pelo PCN de Ciências da Natureza, Matemática e suas Tecnologias (BRASIL,1999), sendo estas: (1) representação e comunicação - desenvolver a capacidade de comunicação dos alunos; (2) investigação e compreensão - desenvolver a capacidade de questionar processos naturais e tecnológicos, identificando regularidades, apresentando interpretações e prevendo evoluções, desenvolvendo o raciocínio e a capacidade de aprender; e (3) contextualização sociocultural - compreender e utilizar a ciência, como elemento de interpretação e intervenção, e a tecnologia como conhecimento sistemático de sentido prático. A partir destas ideias podemos compreender a necessidade de se criar um currículo contextualizado historicamente, unindo as habilidades e competências dos PCN numa proposta crítica. Desta maneira, durante o processo de construção da nossa proposta foi pensado um currículo que unisse a história social da ecologia com sua história natural.

Salientamos, ainda, que os temas contidos em nossa proposta curricular podem ser amplamente trabalhados em sala e que os conceitos da ecologia podem ser ensinados com um nível de aprofundamento a escolha do professor, conforme aponta os PCN (BRASIL,1997) quando trazem que o professor deve julgar a pertinência de aprofundamento de estudo em alguns temas e a exploração mais ampla de outros, tendo como base os critérios de seleção de conteúdos aplicados à sua realidade e contexto do aluno.

\section{2 Relação do currículo proposto com o Currículo Básico Comum - CBC}

Diversos temas da nossa proposta curricular são correspondentes com algumas diretrizes trazidas pelo CBC (MINAS GERAIS, 2007), porém nem todos os temas foram encontrados nesse documento. Após a comparação da nossa proposta com o CBC, foi possível perceber que alguns temas encontrados nela, ligados à ecologia social e que são de fundamental importância para a formação dos alunos, não são abordados no Conteúdo Básico Comum de Biologia (quadro 2).

\section{Quadro 2 -Temas propostos que não são encontrados explicitamente no CBC.}

\begin{tabular}{|l|l|}
\hline Item & Temas \\
\hline 03 & Biocenose e Comunidade \\
\hline 05 & Nicho Ecológico \\
\hline 06 & Teorias Policlímax,monoclímax e Sucessão Ecológica \\
\hline 09 & Ecologia da paisagem \\
\hline 10 & Forrageio ótimo (Teoria da otimização e energética) \\
\hline 13 & Biogeografia de Ilhas \\
\hline 14 & Interações ecológicas \\
\hline
\end{tabular}

Fonte: dos autores.

Os conteúdos de Ecologia presentes no CBC se encontram de certa forma em dissonância com a proposta curricular elaborada e mesmo com os Parâmetros Curriculares Nacionais (BRASIL, 1998), pois os conteúdos se apresentam de forma fragmentada, e pouco contextualizados, tornado a Ecologia uma ciência distante da realidade dos alunos, além de muitas vezes ser insipiente na abordagem de alguns temas, como por exemplo a ideia de ecossistema. Vale destacar ainda, que o documento é bastante "engessado" e que não apresenta possibilidade para que o educador estabeleça caminhos metodológicos diferenciados, tornando muitas vezes o ensino monótono. Isso se deve ao fato de que o documento se apresenta de uma forma muito segmentada, impedindo muitas vezes, que $o$ professor crie diálogos entres os conceitos, pois estes “obedecem”, de certo modo, uma lógica estrutural contida no programa. Além disso, o professor muitas vezes não consegue mudar essa estrutura devido à cobranças e pressões externas, como por exemplo a fiscalização da Superintendência de Ensino do estado de Minas Gerais. 
O tema Ecologia é pouco mencionado e as temáticas apresentadas se encontram diluídas ao longo do currículo do ensino médio. Muitos temas que foram escolhidos para compor a nossa proposta foram pensados por fazerem parte da história social e natural da Terra e da humanidade, e da própria ciência Ecologia, porém não encontram correspondência no documento oficial do governo do estado de Minas Gerais. Mesmo aqueles que encontram correlação, são de forma parcial e até mesmo superficial, nos fazendo perceber certo esvaziamento de conteúdos essenciais para a formação dos alunos.

\section{3 Comparação do currículo proposto na disciplina com os livros didáticos utilizados no ensino médio das escolas públicas de Lavras - MG}

Neste trabalho, foram avaliados os livros didáticos de seis escolas estaduais do município de Lavras - MG para que pudéssemos compará-los com a proposta construída na disciplina. As análises realizadas se concentraram nas temáticas de Ecologia que cada livro traz. Os livros utilizados nas Escolas Públicas de Lavras estão relacionados (Quadro 3) a seguir:

\section{Quadro 3 - Relação dos livros utilizados pelas escolas estaduais.}

\begin{tabular}{|l|l|}
\hline Livros Utilizados & Escolas \\
\hline Biologia Hoje (Editora Ática, 2011) & E.E. “Cristiano de Souza”; \\
\hline Biologia 1, 2, 3 (Editora Moderna, 2010) & E.E. “João Batista Hermeto”; E.E. “Dora Matarazzo”; \\
\hline Ser Protagonista (Editora SM Didáticos, 2009) & E.E “Cinira Carvalho”; E.E “Firmino Costa”; E.E. “Azarias Ribeiro”. \\
\hline
\end{tabular}

Fonte: dos autores.

O livro Biologia Hoje é utilizado no primeiro, segundo e terceiro anos do ensino médio da Escola Estadual Cristino de Souza, cuja autoria é de Sérgio Linhares e Fernando Gewandsznajder. Ao compararmos a Unidade III deste livro, cujo foco é a Ecologia, com a nossa proposta de conteúdos podemos notar que grande parte dos tópicos se encontram de acordo com a nossa proposta, como por exemplo, a temática de interações ecológicas, conceitos de nicho, habitat, população, etc. Contudo, vale ressaltar que o tema "Poluição" aparece no livro de forma diferente da nossa proposta curricular. Não há em nossa proposta um foco específico para os tipos de poluição (radioativa, sonora, visual, etc.) como no livro, pois compreendemos que tal temática está imbricada numa abordagem socioambiental dos ecossistemas de forma geral. Assim, ao trabalhar com diversas temáticas presentes em nossa proposta, o professor poderá trazer essas discussões a fim de contemplar este conteúdo.

As Escolas Estaduais “João Batista Hermeto" e "Dora Matarazzo" utilizam o livro didático Biologia Volume 1, 2, 3 de José Mariano Amabis e Gilberto Rodrigues Martho. O volume 3, que é utilizado no $3^{\circ}$ ano do Ensino Médio, é que contém a parte de Ecologia. Essa parte se subdivide em seis eixos principais que, conforme nossa análise dialoga bastante com a proposta que construímos. Podemos, de modo geral, dividi-las em dois blocos: o primeiro como a "A ciência Ecologia, seus conceitos fundamentais (indivíduos, população, comunidade e ecossistema; fluxo de matéria energia; sucessão ecológica, etc.) e o segundo como "Ambiente e humanidade" que engloba desde as dinâmicas dos processos naturais até a interferência humana em ecossistemas naturais. Vale ressaltar que os eixos “Teorias Policlímax e Monoclímax", "Ecologia da paisagem”, "Forrageio ótimo (Teoria da otimização e energética)” que estão em nossa proposta, não estão presentes nesse livro didático.

O livro utilizado nas escolas Estadual Azarias Ribeiro, Estadual Cinira de Carvalho, e Estadual Firmino Costa é o livro "Biologia - Ser Protagonista" de Fernando Santiago dos Santos, João Batista Vicentin Aguilar, Maria Martha Argel de Oliveira. Neste livro os conteúdos apresentados para o $1^{\circ}$ e $2^{\circ}$ não abordam temas de Ecologia, somente no $3^{\circ}$ ano do ensino médio. Podemos identificar que grande parte dos temas presentes em nossa proposta compõem o livro didático, porém a abordagem no livro é bastante diferente, pois não se trata de uma proposta integrada e que contextualizada. Alguns eixos da nossa proposta não são abordados no livro, como as "Teorias Policlímax e Monoclímax”; “Ecologia da paisagem e Forrageio ótimo (Teoria da otimização e energética)”. 


\section{CONCLUSÕES}

A partir da avaliação realizada, a comparação da proposta elaborada com o currículo oficial e os livros didáticos adotados pelas escolas, podemos perceber que o currículo oficial (CBC) é, em muitos aspectos, fragmentado e pouco contextualizado. Podemos observar isso também na diluição do conteúdo de Ecologia ao longo dos temas no CBC e na pouca presença do tema sendo sugerido de forma contextualizada e com diálogos com a formação cidadã dos educandos, sendo apresentados, muitas vezes, numa perspectiva pouco crítica.

Ao analisarmos os livros didáticos, podemos perceber que os conteúdos são organizados numa abordagem pouco integrada o que pode dificultar a apropriação dos conteúdos relacionados à Ecologia pelos educandos. É necessário ainda destacar, que na proposta elaborada na disciplina, buscamos utilizar a História como elemento contextualizador pois, acreditamos que os alunos consigam se situar melhor, no tempo e espaço histórico, ao conhecerem a trajetória da construção dos conhecimentos e teorias científicas ao longo do tempo.

Portanto, podemos considerar que a abordagem da Ecologia construída em nossa proposta curricular é coerente com o perfil de formação que acreditamos ser necessário para a construção de uma sociedade mais justa e igualitária. Além de que os temas propostos são importantes na formação dos educandos, uma vez que perfazem a vida humana. Nesse sentido, compreendemos que conhecimento acerca da Ecologia, torna-se fundamental para a formação de um cidadão crítico que valorize a vida como um todo, buscando a preservação e o equilíbrio do nosso planeta. 


\section{REFERÊNCIAS BIBLIOGRÁFICAS}

BEGON, M; TOWNSEND, C. R.; HARPER, J.L. Ecologia de indivíduos a ecossistemas. $4^{\mathrm{a}}$ Edição. Porto Alegre: Artmed Editora S/A, 2007, 740 p.

BRASIL. Secretaria de Educação Média e Tecnologia. Parâmetros Curriculares Nacionais: terceiro e quarto ciclos do ensino fundamental - ciências naturais. Brasília. MEC/SEMTEC. 1998.

Secretaria de Educação Média e Tecnologia. Parâmetros Curriculares Nacionais: Ciências da natureza, matemática e suas tecnologias. Brasília. MEC/SEMTEC. 1999.

Ministério da Educação. Secretaria da Educação Média e Tecnológica. Parâmetros Curriculares Nacionais + (PCN+) - Ciências da Natureza e suas Tecnologias. Brasília: MEC, 2002.

DUARTE, M. C. A história da ciência na prática de professores portugueses: implicações para a formação de professores de ciências. Ciência \& Educação, v. 10, n. 3, p. 317-331, 2004.

MOREIRA, A. F. B.; SILVA, T. T. (Orgs.). Sociologia e teoria crítica do currículo: uma introdução. In: Currículo, cultura e sociedade. 2. ed. São Paulo: Cortez, 1997.

MOREIRA, A. F. B.; SILVA, T. T. (Orgs.). Currículo, cultura e sociedade. São Paulo: Cortez, 1994.

OLIVEIRA, R. A.; SILVA, A. P. B. . A história da ciência no ensino: diferentes enfoques e suas implicações na compreensão da ciência. In: III CONGRESSO DE PÓS-GRADUAÇÃO E PESQUISA E XVIII ENCONTRO DE INICIAÇÃO CIENTÍFICA, 2011, Campina Grande. ANAIS DO XVIII ENCONTRO DE INICIAÇÃO CIENTÍFICA, 2011.

SANTOS, A. R. J.. Currículo e educação: conceito e questões no contexto educacional. In: VIII CONGRESSO NACIONAL DE EDUCAÇÃO DA PUCPR - EDUCERE E III CONGRESSO IBERO-AMERICANO SOBRE VIOLÊNCIAS NAS ESCOLAS - CIAVE, 2008, Curitiba. ANAIS DO VIII CONGRESSO NACIONAL DE EDUCAÇÃO DA PUCPR - EDUCERE E III CONGRESSO IBERO-AMERICANO SOBRE VIOLÊNCIAS NAS ESCOLAS - CIAVE, 2008.

SILVA, M. A.. História do currículo e currículo como construção histórico- cultural. In: VI CONGRESSO LUSO-BRASILEIRO DE HISTÓRIA DA EDUCAÇÃO, 2006, Uberlândia. ANAIS DO VI CONGRESSO LUSO-BRASILEIRO DE HISTÓRIA DA EDUCAÇÃO, Uberlândia, 2006.

SILVA, T. T. Documentos de identidade: uma introdução às teorias do currículo. 3. ed. Belo Horizonte: Autêntica, 2010. 